\section{Postgraduate ophthalmic training: how do we compare?}

WH Chan'1, H Saedon ${ }^{2}$ and MG Falcon ${ }^{3}$
The advent of Modernising Medical Careers and the subsequent transition from the old style Senior House Officer (SHO) and Specialist Registrar (SpR) grades, to the new unified run-through grade, has caused much anxiety among junior doctors regarding the quality of their training and subsequent career prospects. ${ }^{1}$ There is reportedly a significant exodus of UK doctors looking for better training overseas, ${ }^{2}$ but how does training abroad fare?

We set out to compare postgraduate training in ophthalmology in the United Kingdom with that in Germany, the United States of America, Australia and New Zealand, and Singapore. These countries were chosen because of their popularity and reputation for good training. The aim of this was to identify the benefits of training in any of the countries considered, from which the other countries could learn, and to identify any specific weak points common to training in some or all countries.

In the United Kingdom, seven-year run-through specialty training began in August 2007. The first 2 years are equivalent to the old SHO grade, years 3-6 the equivalent of the SpR grade, and year 7 spent in advanced subspecialty training as a trainee selected component. This may then be followed by a fellowship in a subspecialty. The curriculum now defines outcomes of training, rather than inputs and processes. There are 180 learning outcomes that must be achieved in order to gain the Certificate of Completion of Training. ${ }^{3}$ Compulsory milestones include the acquisition of the Fellowship examination and the Refraction Certificate, which have replaced the old MRCOphth diploma and Fellowship assessment.

The previous curriculum identified seven subspecialties (oculoplastics and orbit, cornea and external diseases, cataract and refractive surgery, glaucoma, retina, neuroophthalmology, and paediatric ophthalmology) to be completed, but a modular approach to training is still used in most deaneries.

The mainstay of surgery remains the cataract extraction and IOL implantation. Indicative numbers are a minimum of 50 cases before ST3 and 350 cases during ST1-7. The trainee must keep a logbook and personal audit data in their portfolio. Typically, a trainee should also have performed a certain number of other procedures by the end of training (Table 1$)^{4}$

Germany has produced many famous ophthalmologists, such as von Graefe, Axenfeld, and Leber. Surprisingly, then, training in the specialty is less structured than one might expect. It begins with an initial period of 4 years in basic training. This qualifies the trainee for a state licence with or without an examination. Surgical training begins after obtaining a faculty position. ${ }^{5}$ In 1998 , only about $25 \%$ of practising ophthalmologists received training in intraocular surgery, mainly after residency. ${ }^{6}$ The minimum duration of training for ophthalmology is 5 years, including the 4 years of basic training, which can take place in any acknowledged institution. Two years of those five years duration may even be in the office of any physician acknowledged for medical training. There is a demand for specialist knowledge and abilities demonstrated with a diploma. ${ }^{7}$ Regional postgraduate courses take place several times a year in most university eye departments. A questionnaire survey found that $48 \%$ of ophthalmology trainees reported exceeding the normal working hours (by law) 4-5 times per week, but several indices indicated enthusiastic career aspirations. All trainees interviewed would favour ophthalmology again when asked which discipline they would choose. ${ }^{8}$ Research is integrated into some programmes and grants may be funded by the German Research
${ }^{1}$ Department of Ophthalmology, Great Ormond Street Hospital for Children, London, UK

\footnotetext{
${ }^{2}$ Department of Ophthalmology, University Hospitals Coventry and Warwickshire and Warwick Medical School, West Midlands, UK

${ }^{3}$ Department of Ophthalmology, St Thomas' Hospital, London, UK

Correspondence: WH Chan, King's Fellow in Paediatric Ophthalmology,

Department of Ophthalmology, Great Ormond Street Hospital, London WC1N 3JH, UK Tel: +44 0207405 9200; Fax: +44 02078298643 . E-mail: wai@doctors.org.uk
} 
Table 1 Number of procedures needed for US residents and typical numbers for UK trainees ${ }^{4,17}$

\begin{tabular}{lcc}
\hline Procedure & United States & United Kingdom \\
\hline Cataract & 86 & 350 \\
Strabismus & 10 & 20 \\
Corneal surgery & 3 & $6^{\mathrm{a}}$ \\
Glaucoma laser and filtering & 14 & 30 \\
Retina/vitreous & $10^{\mathrm{a}}$ & 20 \\
Other retinal & 25 & 40 \\
Oculoplastics and orbit & 28 & $40+$ assisted at \\
Globe trauma & \multicolumn{3}{c}{3 ptosis procedures } \\
\hline
\end{tabular}

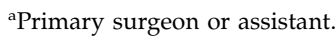

Council. There is no time limit to training and true independence of practice may only be reached when the individual is given a chair.

In the United States, ophthalmology residencies remain competitive to obtain because they enable a controllable lifestyle. ${ }^{9}$ A survey of residents from 1992 indicated a high level of satisfaction with their training. ${ }^{10}$ However, it has been suggested that training has become neglected, with limited experience being gained in many procedures. ${ }^{11,12}$ Since 2002, there has been a new curriculum and a paradigm shift to competency-based residency training. ${ }^{13,14}$

Doctors undertaking the 3-year residency must satisfy the standard requirements of patient care, knowledge, practice-based learning, communication skills, and professionalism. ${ }^{15}$ Surgical exposure is limited in the first year, but increases rapidly, without the constraints of a 48-h week imposed by the European Working Time Directive. ${ }^{16}$ American residents typically work $60 \mathrm{~h}$ per week. ${ }^{14}$ The resident must also participate in a minimum number of procedures (Table 1). ${ }^{17}$

Medical education is both structured and conference based, totalling $360 \mathrm{~h}$. Residents are also required to train for $36 \mathrm{~h}$ in ocular pathology. Outpatient experience must consist of a minimum of 3000 outpatient visits. ${ }^{18}$ After 3 years they are eligible to become a Diplomate of the American Board of Ophthalmology, a specialist in their own right. They are then certified for 10 years. They may then either practise general ophthalmology or begin a fellowship in a subspecialist area, typically for 1 or 2 years. ${ }^{19}$ A perceived lack of knowledge by newly qualified ophthalmologists is indicated by a survey, which showed that $49 \%$ desired additional training in certain clinical knowledge areas. ${ }^{20}$

Specialist training in Australia and New Zealand takes 5 years. ${ }^{21}$ There is an induction period of 3 months, after which the candidate must be able to obtain and record an appropriate history, perform eye examinations, manage ocular emergencies, carry out and interpret diagnostic tests, and show the expected standard of professionalism. These skills are also assessed in 'on-job' assessments and the Ophthalmic Basic Competencies and Knowledge examination, which must be passed within the first 18 months of training. ${ }^{22}$

Advanced training builds on the skills learnt in basic training. Integrated clinical and surgical skills are assessed in the fourth year of training in the Advanced Pathology Examination and the Royal Australian and New Zealand College of Ophthalmologists Advanced Clinical Examination. ${ }^{23}$ The final year of training is to broaden experience, preferably in a different institution with many being funded to travel as overseas fellows in the United Kingdom, Canada, and the United States of America. Following completion of this final year of training by the College, the candidate is eligible to apply to become a Fellow of the College and be a specialist in his own right. ${ }^{24}$

Ophthalmology training in Singapore is modelled on the old British system in conjunction with the Royal College of Surgeons of Edinburgh. Plans are underway to move to a US-based programme to allow more room for close mentoring. ${ }^{25}$ The College of Ophthalmologists was formed on 20 January 2009, under the Academy of Medicine, Singapore. ${ }^{26}$ Doctors sit the Singapore Master of Medicine in Ophthalmology (Primary MMed (Ophthalmology)) and/or the Joint Primary MMed (Ophthalmology)/FRCSEd Examination. Primary MMed consists of FRCS Parts 1 and 2 and Refraction Assessment. These may be sat any time following commencement of postgraduate training. ${ }^{27}$

Trainees must then complete an additional 3-4 years of Advanced Specialist Training, culminating in an exit examination, Final MMed, which may be taken after 30 months' of ophthalmology training. ${ }^{28}$ A logbook must also be kept but does not form part of the formal examination. Fellowship of the Academy of Medicine may also be obtained and successful candidates may apply for specialist accreditation. A year's subspecialty training may then follow.

There are more similarities than differences between the ophthalmic postgraduate training schemes that we have discussed herein (Table 2). Training is particularly long in the United Kingdom and Singapore, but is well structured and research is encouraged, though not essential. Surgical training begins much later in Germany, with much greater emphasis on medical Ophthalmology. It is interesting to note that despite a short training programme in the United States of America, they have a long tradition of leading the way with innovative techniques in the field. This is most like due to the high expenditure on healthcare and the more affluent American universities. The International Council 
Table 2 Summary of training

\begin{tabular}{|c|c|c|c|}
\hline Country & $\begin{array}{l}\text { Age at } \\
\text { entry } \\
\text { (years) }\end{array}$ & $\begin{array}{l}\text { Years of } \\
\text { training }\end{array}$ & Exams \\
\hline $\begin{array}{l}\text { United } \\
\text { Kingdom }\end{array}$ & 25 & $\begin{array}{l}7 \text { Years } \\
\text { run-through, } \\
1-2 \text { Fellow }\end{array}$ & FRCOphth \\
\hline Germany & 24 & Minimum 5 years & Facharztprüfun \\
\hline $\begin{array}{l}\text { United States } \\
\text { of America }\end{array}$ & 28 & $\begin{array}{l}3 \text { Years residency, } \\
2 \text { Fellow }\end{array}$ & $\mathrm{ABO}$ \\
\hline Australia & 25 & $\begin{array}{l}5 \text { Years residency, } \\
1 \text { Fellow }\end{array}$ & FRANZCO \\
\hline Singapore & 24 & $\begin{array}{l}3 \text { Years BST, } \\
4 \text { AST }\end{array}$ & FRCS Ed/MMe \\
\hline
\end{tabular}

of Ophthalmology in its publication, Vision for the Future, announced its commitment to assist in the development of curricula for international use. ${ }^{29}$ The ideal training programme should be provided through a balance of formal teaching, supervised patient care, and hands-on procedural and surgical experience. Research should be encouraged, as should independent study and lifelong learning, so that the specialty continues to evolve.

\section{Conflict of interest}

The authors declare no conflict of interest.

\section{References}

1 Lynn E. Poll highlights frustration with changes in UK medical training. BMJ News 2007; 335: 174

2 Boseley S. Junior doctors driven abroad by new system. Guardian, 2 March 2007.

3 http://curriculum.rcophth.ac.uk/learning-outcomes/. Accessed 10 September 2010.

4 Guide for the delivery of OST. Available at http:// www.rcophth.ac.uk/page.asp?section=322\&sectionTitle= Guides+and+Curricula.

5 Naumann GO. Ophthalmology in Germany. Arch Ophthalmol 1998; 116: 1366-1368.

6 Kirkness CM. European ophthalmology from a British perspective. Br J Ophthalmol 2002; 86(2): 128-129.

7 Dilger K. Are graduate education requirements in ophthalmology in Germany compatible with European standards?]. Klin Monbl Augenheilkd 1994; 204(5): 478-481 (Article in German).

8 Meltendorf C, Ziemssen F. Arbeitsgruppe Nachwuchs der Deutschen Ophthalmologischen Gesellschaft [Working conditions for young trainees and junior researchers in ophthalmology: results of a recent online questionnaire]. Ophthalmologe 2010; 107(12): 1176-1184 (Article in German).
9 Dorsey ER, Jarjoura D, Rutecki GW. Influence of controllable lifestyle on recent trends in specialty choices by US medical students. JAMA 2003; 290: 1173-1178.

10 Pankratz MJ, Helveston EM. Ophthalmology: the resident's perspective. Arch Ophthalmol 1992; 110(1): 37-43.

11 Quillen DA, Harper RA, Barrett GH. Medical student education in ophthalmology: crisis and opportunity. Ophthalmology 2005; 112(11): 1867-1868.

12 Rosen ES. Moving with the times. J Cataract Refract Surg 2004; 30: 1147-1149.

13 Lee AG. The New competencies and their impact on resident training in ophthalmology. Surv Ophthalmol 2003; 48(6): 651-662.

14 Liesegang TJ, Hoskins Jr HD, Albert DM, O’Day DM, Spivey BE, Sadun AA et al. Ophthalmic education: where have we come from, and where are we going? Am J Ophthalmol 2003; 136(1): 114-121.

15 http://www.abop.org/maintain/. Accessed 15 September 2010.

16 Simpson C, Cottam H, Fitzgerald JE, Giddings CE. The European working time directive has a negative impact on surgical training in the UK. Surgeon 2011; 9(1): 56-57.

17 http://www.acgme.org/acWebsite/RRC_240/240_ MinimumsOperativeTable.pdf. Accessed 19 September 2010.

18 Office for National Statistics. Outpatient referral rates per 1000 patient years at risk, by clinical speciality, age, sex and country/region: 1994-1998. Key Health Statistics from General Practice 1998, Table 6B1.

19 Accreditation Council for Graduate Medical Education. Program Requirements for Residency Education in Ophthalmology, September 2005.

20 McDonnell PJ, Kirwan TJ, Brinton GS, Golnik KC, Melendez RF, Parke II DW et al. Perceptions of Recent Ophthalmology Residency Graduates Regarding Preparation for Practice Ophthalmology. 2007; 114(2): 387-391.

21 Kowal L. Pediatric ophthalmology in Australia. J AAPOS 2003; 7(5): 311-313.

22 Ophthalmic Basic Competencies and Knowledge. Royal Australian and New Zealand College of Ophthalmologists, August 2004

23 http://www.ranzco.edu/training/trainee-assessment/ ranzco-advanced-clinical-examination-race/aboutthe-ranzco-advanced-clinical-examinations-race/. Accessed 4 May 2011.

24 http://www.ranzco.edu/training/3-overview-of-vtp/ fellowship-eligibility/eligibility-for-fellowship/. Accessed 4 May 2011.

25 http://medicine.nus.edu.sg/medoph/about/about.htm Accessed 10 September 2010.

26 http://www.ams.edu.sg/chapter/chapter.aspx. Accessed 10 September 2010.

27 http://www.med.nus.edu.sg/dgms/about_us.shtml. Accessed 10 September 2010.

28 http://medicine.nus.edu.sg/dgms/prog_courses.shtml. Accessed 10 September 2010.

29 Tso MO, Goldberg MF, Lee AG, Selvarajah S, Parrish II RK, Zagorski Z. An international strategic plan to preserve and restore vision: four curricula of ophthalmic education. Am J Ophthalmol 2007; 143(5): 859-865. 